\title{
Effect of Intercriticle Annealing on Impact energy and Hardness of AISI 1026steel
}

\author{
Siluveru Ramakrishna, D. Venkatarramaniah, T.Sitaram Babu, C.Shravani
}

\begin{abstract}
In the advanced planning world, expansive research has incited the improvement of some phenomenal dimensions of steel, every now and again fitting for overhauled limits. Medium carbon steel AISI 1026 is one such assessment, having huge applications in power plants, vehicle and diverse current applications. Diverse warmth treatment forms are utilized to accomplish high hardness and durability, however machinability consequently diminishes. Existing writing isn't adequate to accomplish a harmony among hardness and machinability. The point of this exploratory work is to decide the hardness esteems and durability changes in AISI 1026 steel, when it is exposed to Annealing saw that high toughness value(impact energy) and moderate hardness. Annealed samples oppressed Intercriticle annealing process that implies heated upto upper critical temperature and water quenched. It is seen that the Intercriticle Annealing (ICA) of the specimens after annealing process achieved better results as compared to as received material AISI 1026steel.
\end{abstract}

Index Terms - Heat treatment, Mechanical properties, Hardness, Toughness, Intercriticle Annealing.

\section{INTRODUCTION}

Heat treatment is a mix of arranged Heating and cooling associated with a particular metal in such ways as to make certain better mechanical properties (hardness, solidness). Annealing, normalizing, tempering and hardening are the most imperative heat treatments much of the time used to change the micro-structure and mechanical properties of designing materials particularly steels. Annealing is the kind of warmth treatment most of the time connected so as to malleable iron or steel materials and its grains becomes refined because of ferrite-pearlite micro-structure. It is utilized where extensions and obvious dimension of

\footnotetext{
Manuscript revised July 12, 2019 and published on September 10, 2019 Siluveru Ramakrishna, Department of Mechanical Engineering, Assistant Professor, Balaji institute of technology and science-Narsampet, telangana, india

D. Venkatarramaniah, Department of Mechanical Engineering, Assistant Professor, Balaji institute of technology and science- Narsampet, telangana, india

T.Sitaram Babu, Department of Mechanical Engineering, Assistant Professor, Balaji institute of technology and science-Narsampet, telangana, india

C.Shravani, Department of Mechanical Engineering, RGUKT-Basar, Telangana, india
}

toughness are required in designing materials. Steels are typically hardened and tempered to enhance their mechanical properties, especially their quality and wear opposition. In intercriticle annealing, the steel or its composite is heated to a temperature sufficiently high to advance the development of austenite, held at that temperature until the ideal measure of carbon has been dissolved and afterward rapidly cooled in oil or water at a reasonable rate. Likewise, in the hardened condition, the steel ought to have $100 \%$ to achieve most extreme yield quality; however it is exceptionally brittle as well and in this manner, as quenched steels are utilized for not very many designing applications. By Annealing, the properties of intercriticle annealed steels could be altered to diminish hardness and increment malleability and effect quality step by step. The subsequent microstructures are bainite or carbide encourage in a framework of ferrite relying upon the treating temperature.

Inter Critical Annealing (ICA):

Intercriticle annealing carried between upper critical temperature $\left(912^{\circ} \mathrm{C}\right)$ and lower critical temperature $\left(723^{\circ} \mathrm{C}\right)$ lines. This inter-critical annealing will improves the hardness of the material.

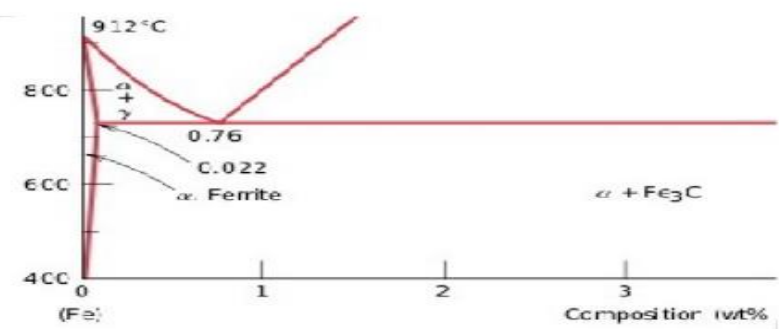

Figure 1: Iron-carbon diagram for representation of ICA

In inter-critical annealing process, the steel material has ferrite and austenite composition and afterheat treatment process, the material will subjected to rapid cooling which means water quenching which results in ferrite will remains as ferrite and austenite changes its structure to martensite. Martensite formation has very hard and brittle in nature.

Table 1.Chemical composition of As Received material AISI1026 steel

\begin{tabular}{|l|l|l|}
\hline S.No & Composition & Percentage \\
\hline 1 & Iron(Fe) & $98.73 \%-99.18 \%$ \\
\hline 2 & Carbon(C) & $0.220 \%-0.280 \%$ \\
\hline 3 & Manganese(Mn) & $0.60 \%-0.90 \%$ \\
\hline 4 & Sulphur(S) & $<=0.050 \%$ \\
\hline 5 & Phosphorous(P) & $<=0.040 \%$ \\
\hline
\end{tabular}


Table 2.Mechanical properties of As Received material AISI1026 steel

\begin{tabular}{|l|l|}
\hline Mechanical properties & Values \\
\hline Tensile strength & $490 \mathrm{MPa}$ \\
\hline Yield strength & $415 \mathrm{MPa}$ \\
\hline Bulk modulus & $140 \mathrm{GPa}$ \\
\hline Shear modulus & $80.0 \mathrm{GPa}$ \\
\hline Elastic modulus & $190-210 \mathrm{GPa}$ \\
\hline Poisson's ratio & $0.27-0.30$ \\
\hline Elongation at break & $15.00 \%$ \\
\hline Reduction of area & $40.00 \%$ \\
\hline Hardness, Brinell & 143 \\
\hline Hardness, Knoop & 163 \\
\hline Hardness, Rockwell B & 78 \\
\hline Hardness, Vickers & 149 \\
\hline Machinability & 75 \\
\hline
\end{tabular}

\section{LITERATURE REVIEW}

Anmol Singh et.al [1] studied the behaviour of mechanical properties of steel alloy specimen in two different phases. In the first phase Low Alloy Steel AISI 8740 specimens were prepared as per ASTM standards and subjected to heat treatment process. Sample was tested before and after the heat treatment process, results are tabulated. In the second phase two Low Alloy Steel AISI 8740 specimens were together welded and followed by Heat treatment process. Samples are subjected to mechanical properties before and after heat treatment. From the results it was noticed that Welding introduces some defects and affects the mechanical properties it was recovered by the heat treatment process for welded alloys. For specimen without welding and the welded specimen, mechanical properties obtained after heat treatment have noticeable margin. Rajesh Jha et.al [2] investigated the mechanical properties on the heat treated Mild Steel specimens. Heat treatment is conducted at $800^{\circ} \mathrm{C}$ and quenching is carried out. It was observed that cast iron properties are reflecting in the heat treated mild steel specimens. Various mechanical tests were conducted on the specimens and data is collected, results that hardness property of the Mild steel increases with heat treatment process. Ahaneku I. E et.al [3] carried out the investigation on the mild steel materials to enhance the mechanical properties by heat treatment process for six specimens followed by quenching with different fluids. Mechanical testing's were conducted and analyzed the results. The mechanical properties are having positive results with the water quench media compare with the other quenching Medias. Adeyinka Adebayo et.al [4] has investigated on the quenching media which effects on the mechanical properties of the heat treated mild steel specimens. Mechanical tests like Tensile test, hardness test and micro structural analysis were carried out and results are recorded. From the results it was concluded that air-cooled specimen had the lesser hardness but shown better ductility nature to the specimens cooled in different media. The groundnut-oil cooled specimen was observed having higher yield and ultimate tensile and having impact on the have a finer grain structure when compared to other samples. Amit
Kumar Tanwe et.al [5] studied the mechanical properties for the low carbon steel and stainless steel using heat treatment process like annealing, quenching and normalizing at $9000^{\circ} \mathrm{C}$ and testing conducted as per ASTM standards on the UTM. Results were analyzed and stated that heat treatment process affects on the mechanical properties of the mild steel and stainless steel materials. Hasan M F et.al [6] investigated the microstructure changes and various mechanical properties by the heat treatment process for steel material. From the results it was justified that heat treatment process increases the mechanical properties of the material also improves the machinability of the material. The mechanical behaviour and microstructures are compared with heat treated unquenched samples with tensile strength. By the result analysis it was concluded that heat treatment impacts on the mechanical and microstructures. Palash Biswas et.al [7] subjected EN9 steel for annealing and normalizing then tempering, the observed results were like, the micro structures of tempered specimens after normalizing process exhibited fine structure, also the hardness values exposed very higher values as compared with as received EN9 steel. Initially as received specimens subjected to annealing, normalizing after that quenching process, and specimens of normalizing process shown satisfactory results. O.R Adetunji et.al [8] differentiated the effects of case hardening and Quenched samples as well on mechanical properties of low carbon steel. Case hardening and water quenching processes happened for same work environment as $950^{\circ} \mathrm{C}$ temperature and 40 min soaking time. But the results were exhibiting that water quenched sample were hardest and case hardened samples were toughest sample, case hardened sample gave the best strain rate values. S.A. Tukur [9] evaluated the mechanical properties for five samples at different heat treatment rates, the as received material for this experimentation AISI304steel, Initially all the samples were heat treated under $660^{\circ} \mathrm{C}$ temperature and processed for air cooling then all five samples heat treated above upper critical temperature range then subjected to water quenching. At middle range temperature $1090^{\circ} \mathrm{C}$ showed the high hardness and preferable microstructure along with good ductility. Adetunji [10] experimented on case hardening and water quenched samples, concluded as the great hardness values are obtained for water quenched samples when compared with the case hardened samples of mild steel rod. Exhibited high strain rate values for case hardened samples then water quenched samples, Avner S. H [11] Tempering is used to soften and improve ductility in metal sequel to stress relief, to reduce brittleness and to make steel tough to resist shock and fatigue, after hardening had been conducted on it by heating the metal to a subcritical temperature.

\section{METHOdOLOGIES}

\section{A. Selection of material:}

Intercriticle annealing experimentation performed on AISI 1026 with dimensions of $75 \mathrm{mmX} 10 \mathrm{mmX} 10 \mathrm{~mm}$, which has good mechanical properties like impact strength and hardness when compared to other medium carbon steel materials. For increasing the mechanical properties of the as received material, it is subjected to ICA for different temperatures. 


\section{B. Heat Treatment}

Seven specimens were carried out for annealing process using a muffle furnace at $925^{\circ} \mathrm{C}, 120$ minutes soaking time. Annealed samples were cooled to normal room temperature in the furnance itself. Intercriticle annealing(ICA) conducted on 6 selected samples at individual temperatures of $750^{\circ} \mathrm{C}$, $770^{\circ} \mathrm{C}$ and $790^{\circ} \mathrm{C}$ with a soaking time of $75,77,80$ minutes respectively.

Table 3: Heat treatment conditions for different temperatures

\begin{tabular}{|l|l|l|l|}
\hline $\begin{array}{l}\text { No of } \\
\text { Samples }\end{array}$ & Temperature & Cooling medium & $\begin{array}{l}\text { Soaking } \\
\text { time }\end{array}$ \\
\hline 7 & $925^{\circ} \mathrm{c}$ & Furnace(Annealed) & $\begin{array}{l}120 \\
\text { mins }\end{array}$ \\
\hline 2 & $750^{\circ} \mathrm{c}$ & $\begin{array}{l}\text { Water } \\
\text { quenched(ICA) }\end{array}$ & $75 \mathrm{mins}$ \\
\hline 2 & $770^{\circ} \mathrm{c}$ & $\begin{array}{l}\text { Water } \\
\text { quenched(ICA) }\end{array}$ & $77 \mathrm{mins}$ \\
\hline 2 & $790^{\circ} \mathrm{c}$ & $\begin{array}{l}\text { Water } \\
\text { quenched(ICA) }\end{array}$ & $80 \mathrm{mins}$ \\
\hline
\end{tabular}

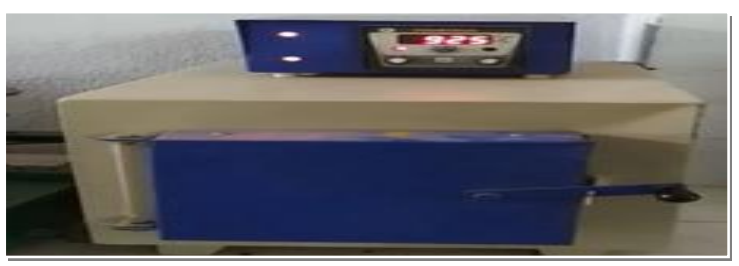

Figure 2: Muffle furnace used for annealing and ICA

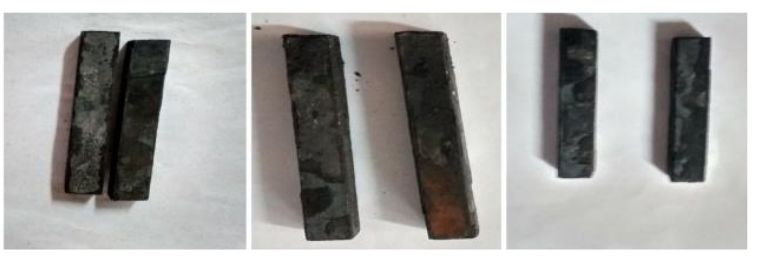

Figure 3: Inter critical annealed samples

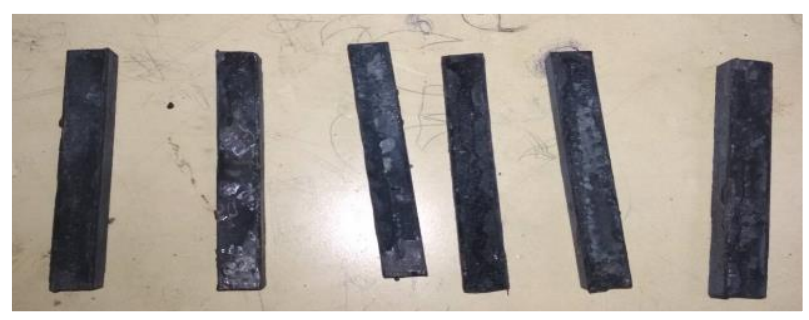

Figure 4: Annealed samples

\section{Hardness Testing:}

Hardness tests were conducted on as-received material, Annealed and Intercriticle Annealed samples to evaluate their hardness properties. A HV-1000 Rockwell type computerized microhardness testing machine was utilized to lead the hardness test estimations. Hardness esteems were dictated by taking the normal of five HRC readings at various positions on the test tests.

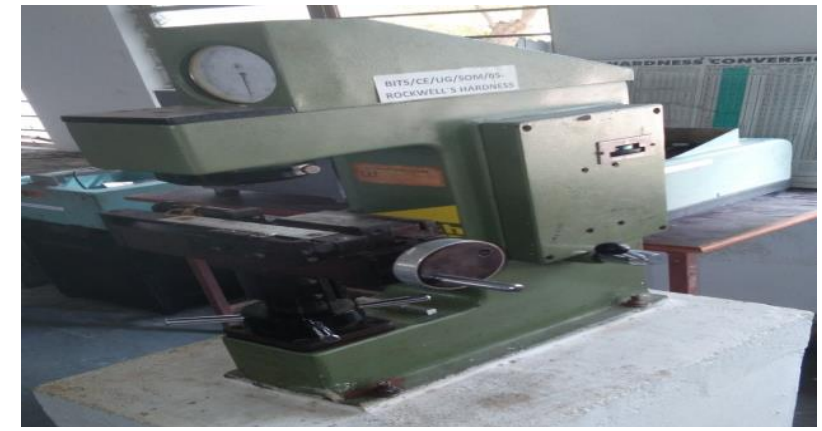

Figure 5: Rockwell hardness testing machine

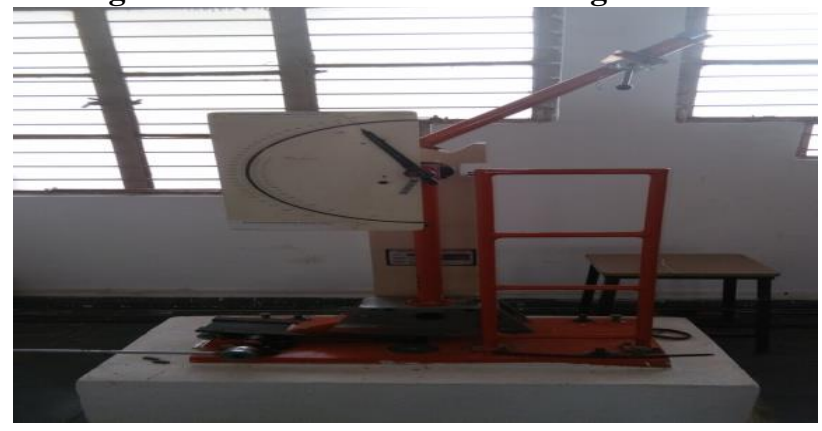

Figure 6: Impact test machine

\section{Impact strength:}

The processed samples were made with a notch, using the standard dimensions. Impact tests (charpy test and izod test) are carried out for the above specimens under Impact Testing Machine and obtained the result of impact strength.

\section{RESUltS AND DisCUSSION}

\section{A. Hardness Test}

The hardness of the annealed and Intercriticle annealed sample was taken using Rockwell hardness tester and the values were tabulated below:

Table 4: Rockwell B-Scale Readings for Annealed and ICA samples

\begin{tabular}{|l|l|l|l|l|}
\hline $\begin{array}{l}\text { Rockwell } \\
\text { B-Scale } \\
\text { Readings }\end{array}$ & Annealed & $\begin{array}{l}\text { Intercriticle } \\
\text { annealed at } \\
\mathbf{7 5 0}^{\circ} \mathbf{C}\end{array}$ & $\begin{array}{l}\text { Intercriticle } \\
\text { annealed at } \\
\mathbf{7 7 0}^{\circ} \mathbf{C}\end{array}$ & $\begin{array}{l}\text { Intercriticle } \\
\text { annealed at } \\
\mathbf{7 9 0}^{\circ} \mathbf{C}\end{array}$ \\
\hline $\begin{array}{l}\text { Hardness } \\
\text { number }\end{array}$ & $\begin{array}{l}58.58 \\
\text { HRC }\end{array}$ & $93.5 \mathrm{HRC}$ & $94.8 \mathrm{HRC}$ & $\begin{array}{l}96.22 \\
\mathrm{HRC}\end{array}$ \\
\hline
\end{tabular}

It is evident from the hardness values that as the Intercriticle temperature are increasing the hardness values are increasing due to the increase in the amount of martensite phase present in the matrix. $\operatorname{In}(\alpha+\gamma)$ region, as the temperature increases the amount of ferrite $(\alpha)$ decreases while the amount of austenite $(\gamma)$ increases. Upon on rapid quenching from this region, austenite transforms to martensite while the ferrite remains the same. The final microstructure contains the islands of martensite in the ferrite matrix. The annealed sample contains a ferrite - pearlite phases while the Intercriticle annealed sample contains ferrite - Martensite Phases. 


\section{B. Impact Energy Test}

Table 5: Impact energy Readings for Annealed and ICA samples

\begin{tabular}{|c|c|c|c|c|}
\hline $\begin{array}{c}\text { Impact } \\
\text { Test }\end{array}$ & Annealed & $\begin{array}{c}\text { Intercriticle } \\
\text { annealed at } \\
\mathbf{7 5 0}^{\circ} \mathbf{C}\end{array}$ & $\begin{array}{c}\text { Intercriticle } \\
\text { annealed at } \\
\mathbf{7 7 0}^{\circ} \mathbf{C}\end{array}$ & $\begin{array}{c}\text { Intercriticle } \\
\text { annealed at } \\
\mathbf{7 9 0}^{\circ} \mathbf{C}\end{array}$ \\
\hline $\begin{array}{c}\text { Izod } \\
\text { test }\end{array}$ & $216 \mathrm{~J}$ & $38 \mathrm{~J}$ & $28 \mathrm{~J}$ & $42 \mathrm{~J}$ \\
\hline $\begin{array}{c}\text { Charpy } \\
\text { test }\end{array}$ & $390 \mathrm{~J}$ & $50 \mathrm{~J}$ & $64 \mathrm{~J}$ & $92 \mathrm{~J}$ \\
\hline
\end{tabular}

From table 5, the results were clearly showing that impact energy of the intercriticle samples were increased with increasing temperature. Impact energy for annealed sample is more as compared with the ICA samples this might due to high amount of ferrite phase in the metal matrix, but whereas for ICA samples depicting less impact energy due to the hard and brittle Martensite phase in ferrite matrix. But within intercriticle annealing the impact energy values were increased with increased temperatures and interestingly for Izod test the impact value from ICA $750^{\circ} \mathrm{C}$ to ICA $770^{\circ} \mathrm{C}$ the impact energy value got decreased due to brittle nature of Martensite formation in the matrix. From the charpy test, the impact energies for ICA samples exhibited better values from ICA $750^{\circ} \mathrm{C}$, ICA $770^{\circ} \mathrm{C}$ and ICA $790^{\circ} \mathrm{C}$ this might be evident for good combination of ductility and hardness. Whereas annealed sample achieved the highest toughness energy values $390 \mathrm{~J}$ due to stress relieve in the material and better formation ferrite and pearlite combination in the metal matrix. For ICA $790^{\circ} \mathrm{C}$ achieved best hardness and impact energy values i.e $96.22 \mathrm{HRC}$ and $92 \mathrm{~J}$. it is evident for best combination of strength and hardness, with this process springback effect can be rectified.

\section{Conclusions}

Conclusions were made based on the results of investigation of effect of heat treatment on mechanical properties of AISI 1026 steel:

1. Hardness, AISI 1026 steel increased while ductility of the material decreased due to Intercriticle annealing effect.

2. As the temperature ranges increase from $750^{\circ} \mathrm{C}$ to $790^{\circ} \mathrm{C}$, amount of martensite formation also increased
3. Intercriticle annealed samples exhibited good strength and higher hardness than annealed samples.

4. Impact energies for Intercriticle Annealed samples increased with increase in the temperatures but as compare with annealed sample it got decreased due to brittle Martensite phase formation.

5. By the Inter critical annealing process achieved hardness values were doubles that of the as received material.

6. ICA $770^{\circ} \mathrm{C}$ and ICA $790^{\circ} \mathrm{C}$ samples were shown best combinations of impact energy and hardness.

\section{REFERENCES}

[1] Anmol Singh, Amit Sharma, Ashish Kumar. "To analyze effect of heat treatment on properties of steel specimen before welding and after welding" International Journal of Engineering Science Invention Research \& Development e-ISSN: 2349-6185.

[2] Rajesh Jha, Siddharth Ranjan,Rakesh Kumar. "Investigation of Heat Treatment on Mechanical Propertiesof Mild Steel" An International Journal of Engineering Sciences,Special Issue November 2017(ETME-17).

[3] Ahaneku, I., A. Kamal, and O. Ogunjirin. "Effects of Heat Treatment on the Properties of Mild Steel Using Different Quenchants." Frontiers in Science 2.6 (2012): 153-158.

[4] Adebayo, Adeyinka, Joseph Temitope Stephen, and Gbenga Joshua Adeyemi. "Effects of Local Cooling Media on the Mechanical Properties of Heat Treated Mild Steel." European Journal of Engineering Research and Science 3.4 (2018): 27-31.

[5] Tanwer, Amit Kumar. "Effect of various heat treatment processes on mechanical properties of mild steel and stainless steel." American International Journal of Research in Science, Technology, Engineering \& Mathematics 8.1 (2014): 57-61.

[6] Hasan MF. "Analysis of Mechanical Behavior and Microstructural Characteristics Change of ASTM A-36 Steel Applying Various HeatTreatment" J Material Sci EngISSN: 2169-0022 JME.

[7] Biswas, Palash, Arnab Kundu, and Dhiraj Mondal. "An Experimental Investigation on Hardness and Microstructure of Heat Treated EN 9 Steel." IOP Conference Series: Materials Science and Engineering. Vol. 225. No. 1. IOP Publishing, 2017.

[8] O.R Adetunji, A.O Adegbola, S.A Afolalu. "Comparative study of case-hardening and water-quenching of mild steel rod on its mechanical properties" International Journal of Advance Research, June 2015, Online: ISSN 2320-9135

[9] Tukur, S. A., et al. "Effect of Heat treatmen t temperature on mechanical properties of the AISI 304 stainless steel." Intl J Innov Res Sci, Eng Technol 3 (2014): 9516-9520.

[10] Adetunji, Olajide R., A. O. Adegbola, and Sunday A. Afolalu. "Comparative study of case-hardening and water-quenching of mild steel rod on its mechanical properties." International Journal of Advance Research, IJOAR. org 3.6 (2015): 1-9.

[11] Avner S. H.,. "Introduction to Physical Metallurgy". McGraw Hill, PP 305-313. Bartel G. E., 2006. "Steel Heat Treatment: Metallurgy and Technologies”. CRC Press: Boca Raton, F.L. 209. 1974.

\section{AUTHORS PROFILE}

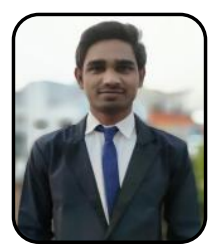

Siluveru Ramakrishna, Assistant Professor in Department of Mechanical Engineering, BITS-Narsampet Completed M.Tech in RGUKT IIIT-BASAR. Have published UGC Approved journals and also present papers in International Conferences. Life time member of ISTE, IAENG, TERA.won many awards and appreciations in educational background.

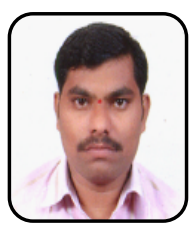

D. Venkatarramaniah, Assistant Professor in Department of Mechanical Engineering, BITS-Narsampet Completed M.Tech in VITS-Bhongir. Have published UGC Approved journals and also present papers in International Conferences. Life time member of ISTE,

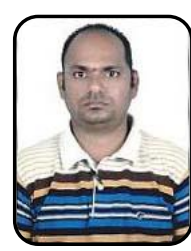

T. Sitaram Babu, Assistant Professor in Department of Mechanical Engineering, BITS-Narsampet Completed M.Tech in Osmania University. Have published 6 UGC Approved journals and also present papers in International Conferences. Life time member of ISTE, IAENG, TERA.

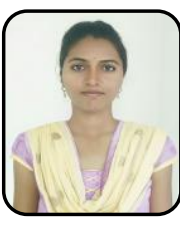

Chiluveri Shravani, Department of Mechanical Engineering, RGUKT IIIT-BASAR. Gold medalist in M.Tech (Computational Mechanics). Have present papers in International Conferences.won many awards and appreciations in educational background. 